مسح عام عن ويائية الأكياس المائية في الأبقار في محافظة الأنبار

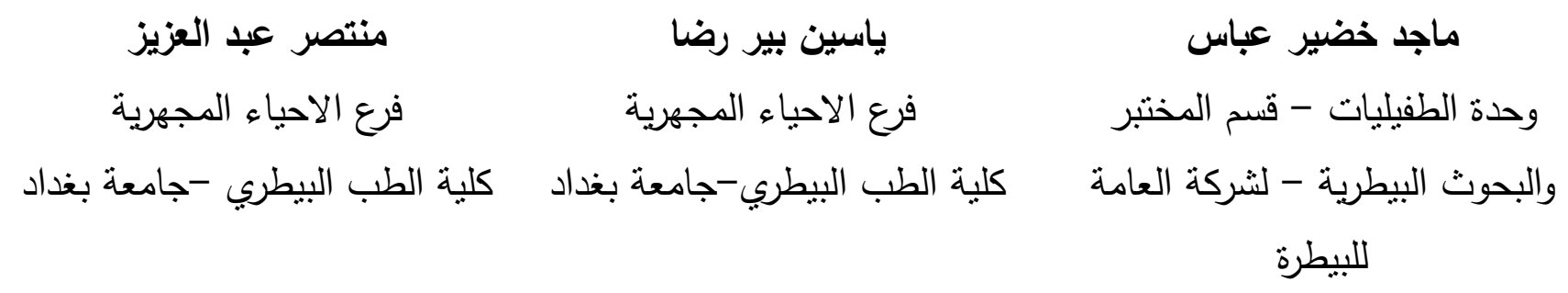

الخلاصة

تم إجراء مسح عن الإصابة بالأكياس المائية في الأبقار في محافظة الأنبار للفترة من 2002/1/1 الأنيا

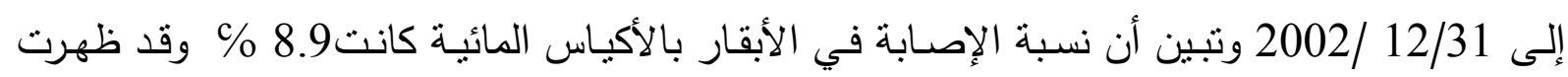

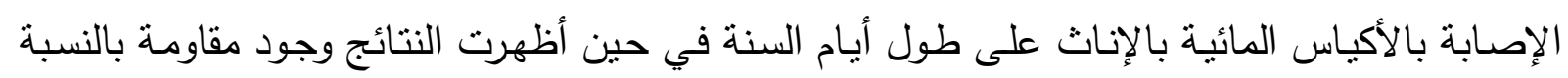

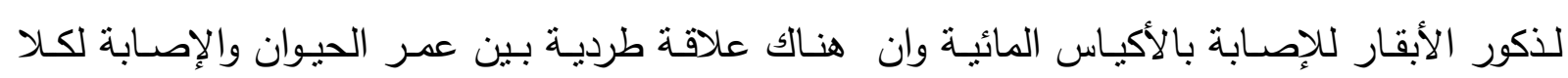

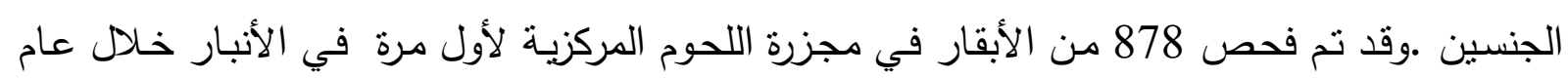

.2002

\title{
Survey Of Hydatidosis In Cattle In Anbar Province During Period From 1/2002-12/2002 \\ M.K.Abbass \\ Y.B.Ridah \\ M.A.Aziz
}

Vet .General State Company

Central Diagnostic Laboratory

Unit of Parasitology
Dept.of microbiology-

College of Vet.Med.

Baghdad University
Dept.of microbiologyCollege of Vet.Med. Baghdad University

\section{SUMMARY}

Survey on distribution of hydatidosis in cattle in Anbar province have been done during period from $1 / 2002-12 / 2002$.This survey showing that $8.9 \mathrm{c}$ of cattle suffering from hydatosis also showing that the infection of cows had been occurred in all months of the year, meanwhile the bulls show resistance to the infection of hydatidosis. There was direct relation between the age of cattle (male\&female)\&infection of hydatidosis .About 879 of slaughtered cattle being inspected in Abattoir of province during the year of 2002 
المقدمسة

داء الأكياس المائية Hydatidosis تسبيه يرقة الدودة الثريطية Echinococcus granulosus وهذا

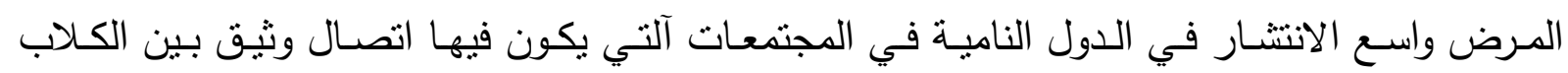

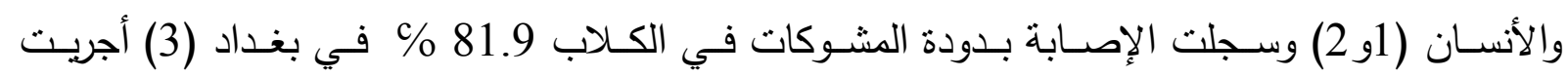

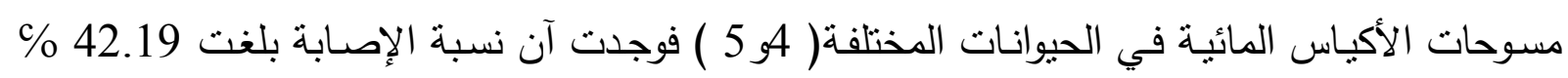

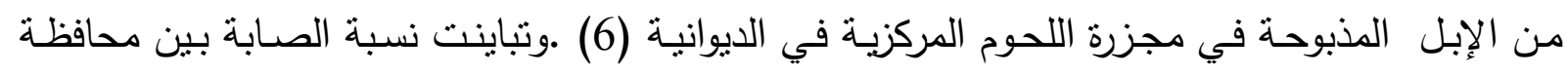
وأخرى في المجترات وكانت 44 \% في أغنام بابل والبصرة (7) كما (8) في الديوانية آن الإصـابة

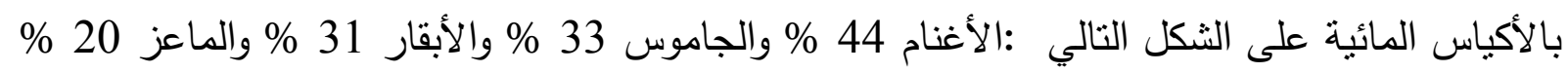
والجمال 6.2

يصاب الأنسان بالأكياس المائية فسجلت حالات كثيرة في الأنسان في محافظات القطر منها 160 حالة

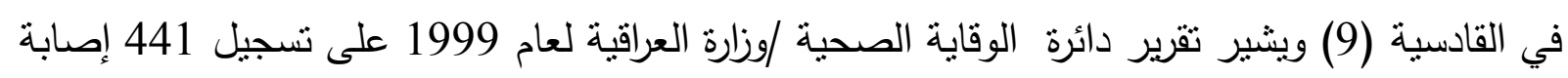

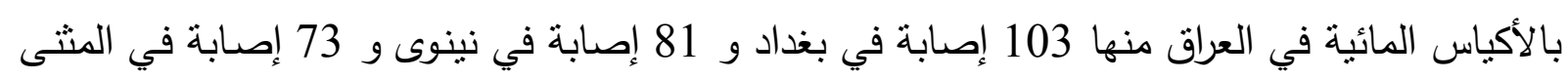

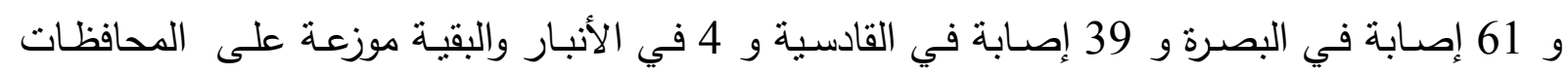

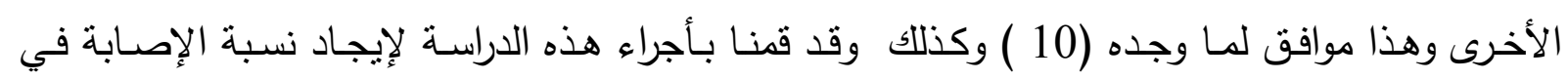
الأكياس المائية في الأبقار في مجزرة اللحوم المركزية في الأنبار لعام 2002

\section{المواد وطرائق العمل}

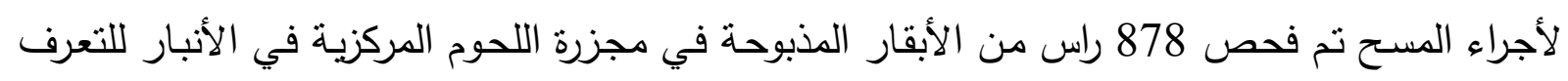

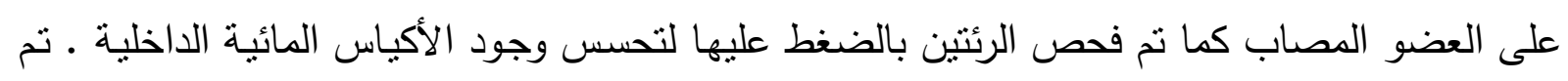

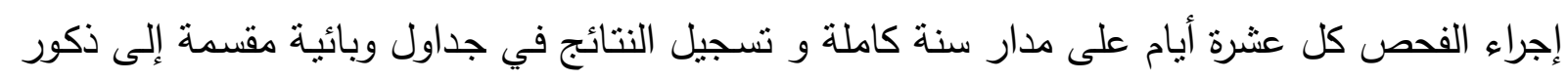
وإناث ,وإناث فقط وذكور فقط . تم فحص على 878 راس من الأبقار المذبوحة خلال عام 2002.

\section{النتائج}

من ملاحظة الجدول(1) كانت النسبة المئوية للإصـابة بالأكياس المائية لإناث وذكور الأبقار بلغت

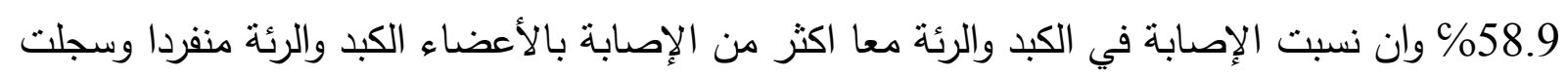

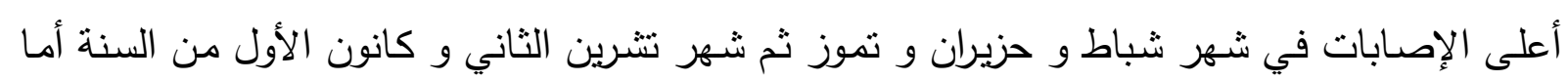

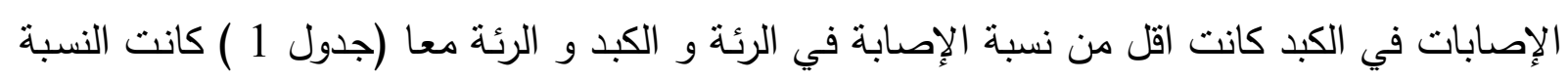

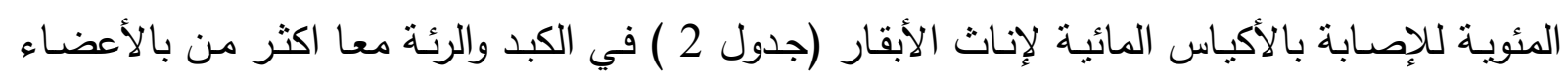


الكبد و الرئة منفردين .أيضا سجلت أعلي الإصابات في شهر شباط وحزيران و تموز ثم شهر تشرين

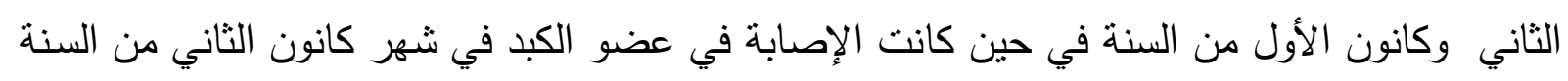

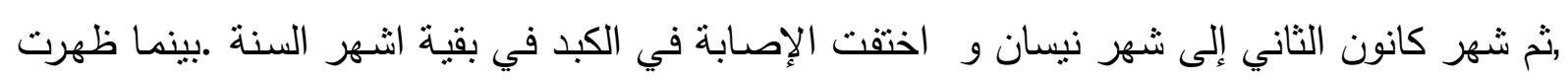

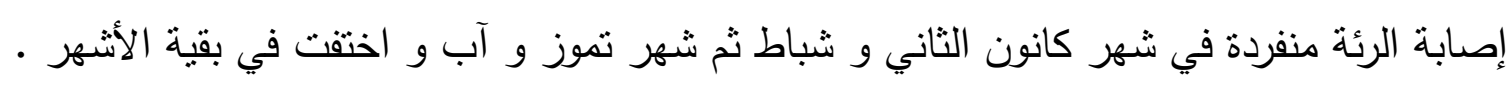

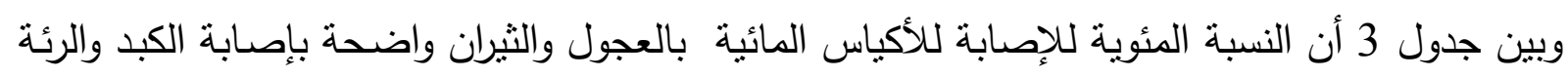
معا وكانت أعلى ما يكون في شهر شباط ثم شهر تموز وآب ثم اختقت الإصابة في بقية الأثشهر وكانت

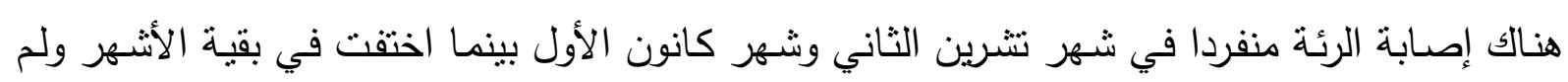
تظهر إصابة في الكبد وحدها طيلة السنة .

جدول( 1): يوضح مستح عام للأصابةبالأكياس المائية لأناث وذكور الأبقار لعام/2002 


\begin{tabular}{|c|c|c|c|c|c|c|c|c|c|}
\hline 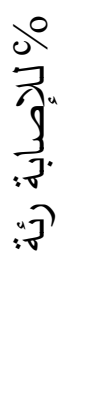 & 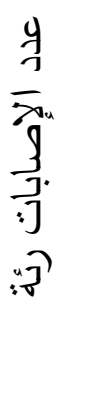 & 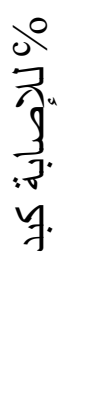 & 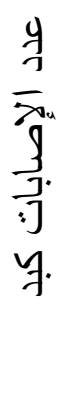 & 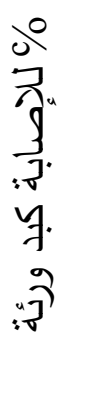 & 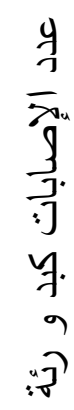 & 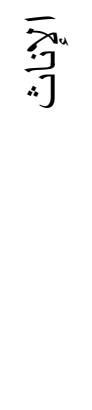 & 学 & 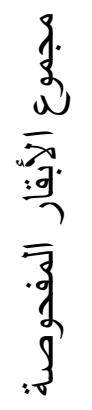 & 虽 \\
\hline 3.2 & 4 & 0.7 & 1 & 2.5 & 3 & 76 & 45 & 121 & كانون الثاني \\
\hline 4 & 3 & 5.2 & 4 & 14.7 & 11 & 47 & 28 & 75 & شباط \\
\hline 0 & 0 & 2.6 & 2 & 4 & 3 & 49 & 26 & 75 & آذار \\
\hline 0 & 0 & 10.3 & 5 & 2.1 & 1 & 29 & 19 & 48 & نيسان \\
\hline 0 & 0 & 0 & 0 & 5.3 & 4 & 38 & 38 & 76 & مايس \\
\hline 0 & 0 & 0 & 0 & 8.3 & 8 & 51 & 44 & 95 & حزيران \\
\hline 1.8 & 1 & 0 & 0 & 17.2 & 9 & 26 & 26 & 52 & تموز \\
\hline 4.4 & 3 & 0 & 0 & 7.6 & 5 & 34 & 32 & 66 & اب \\
\hline 0 & 0 & 0 & 0 & 1.5 & 1 & 30 & 38 & 68 & أبلول \\
\hline 0 & 0 & 0 & 0 & 2.8 & 2 & 24 & 55 & 69 & تثرين الأول \\
\hline 1.4 & 1 & 0 & 0 & 4.5 & 3 & 10 & 55 & 65 & تشرين الثاني \\
\hline 1.5 & 1 & 0 & 0 & 4.3 & 3 & 11 & 57 & 68 & كانون الأول \\
\hline 1.5 & 13 & 1.4 & 12 & 6.2 & 53 & 425 & 463 & 878 & المجموع \\
\hline
\end{tabular}

جدول( 2): يوضح مسح عام للإصابة بالأكياس المائية لإناث الأبقار لعام 2002 


\begin{tabular}{|c|c|c|c|c|c|c|c|}
\hline 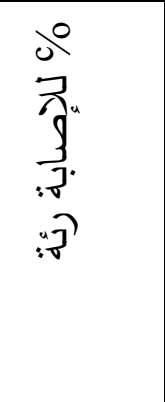 & 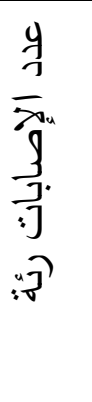 & 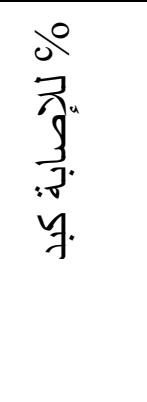 & 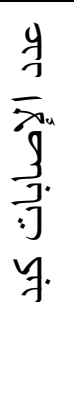 & 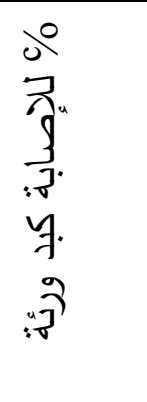 & 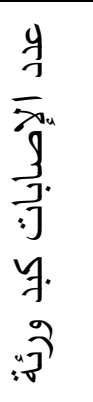 & 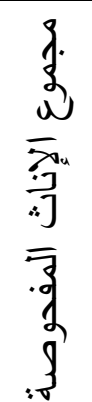 & 電 \\
\hline 5.3 & 4 & 1.2 & 1 & 3.8 & 3 & 76 & كانون الثاني \\
\hline 4.2 & 2 & 2.1 & 1 & 19.1 & 9 & 47 & شباط \\
\hline 0 & 0 & 4.1 & 2 & 5.1 & 3 & 49 & آذار \\
\hline 0 & 0 & 17.3 & 5 & 3.3 & 1 & 29 & نيسان \\
\hline 0 & 0 & 0 & 0 & 10.4 & 4 & 38 & مايس \\
\hline 0 & 0 & 0 & 0 & 15.7 & 8 & 51 & حزيران \\
\hline 0 & 1 & 0 & 0 & 0 & 8 & 26 & تموز \\
\hline 8.7 & 3 & 0 & 0 & 11.7 & 4 & 34 & آب \\
\hline 0 & 0 & 0 & 0 & 3.2 & 1 & 30 & أيلول \\
\hline 0 & 0 & 0 & 0 & 8.2 & 2 & 24 & تشرين الأول \\
\hline 0 & 0 & 0 & 0 & 30 & 3 & 10 & تشرين الثاني \\
\hline 0 & 0 & 0 & 0 & 27.3 & 3 & 11 & كانون الأول \\
\hline $\begin{array}{c}2.4 \\
\text { (المعدل) }\end{array}$ & 10 & $\begin{array}{c}2 \\
\text { (المعدل) }\end{array}$ & 9 & $\begin{array}{c}11.4 \\
\text { (المعدل) }\end{array}$ & 49 & 425 & الدجموع \\
\hline
\end{tabular}


جدول( 3): يوضح مستح عام للإصابة بالأكياس المائية لذكور الأبقار 2002

\begin{tabular}{|c|c|c|c|c|c|c|c|}
\hline 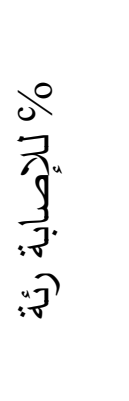 & 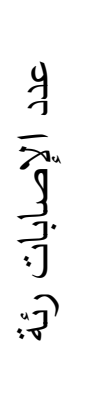 & 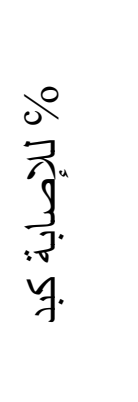 & $\begin{array}{ll}\frac{y}{7} & \\
\bar{z}_{\alpha} & y \\
\frac{3}{3} \cdot & \end{array}$ & 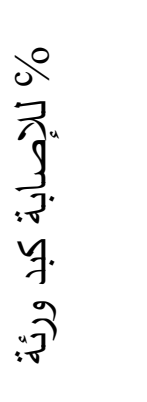 & 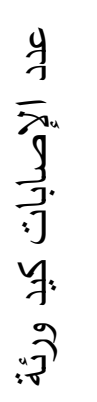 & 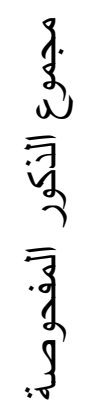 & 可 \\
\hline 0 & 0 & 0 & 0 & 0 & 0 & 45 & كانانون \\
\hline 3.6 & 1 & 1.1 & 3 & 7 & 2 & 28 & شباط \\
\hline 0 & 0 & 0 & 0 & 0 & 0 & 26 & آذار \\
\hline 0 & 0 & 0 & 0 & 0 & 0 & 19 & نيسان \\
\hline 0 & 0 & 0 & 0 & 0 & 0 & 38 & مايس \\
\hline 0 & 0 & 0 & 0 & 0 & 0 & 44 & حزيران \\
\hline 0 & 0 & 0 & 0 & 3.7 & 1 & 26 & تموز \\
\hline 0 & 0 & 0 & 0 & 3 & 1 & 32 & آب \\
\hline 0 & 0 & 0 & 0 & 0 & 0 & 38 & أيلول \\
\hline 0 & 1 & 0 & 0 & 0 & 0 & 55 & تشرين \\
\hline 1.7 & 0 & 0 & 0 & 0 & 0 & 55 & تشثرين \\
\hline 1.6 & 1 & 0 & 0 & 0 & 0 & 57 & كالأون \\
\hline $\begin{array}{c}0.5 \\
\text { (معدل) }\end{array}$ & 3 & $\begin{array}{c}0.1 \\
\text { (معدل) }\end{array}$ & 3 & $\begin{array}{c}1.1 \\
\text { (معدل) }\end{array}$ & 4 & 463 & المجموع \\
\hline
\end{tabular}

\section{المناقثة}

ظهرت الإصابة بالأكياس المائية في ذكور وإناث الأبقار عالية في الأشهر آلتي يكون فيها إجهاد للحيوان

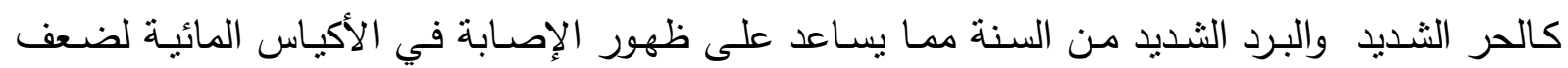

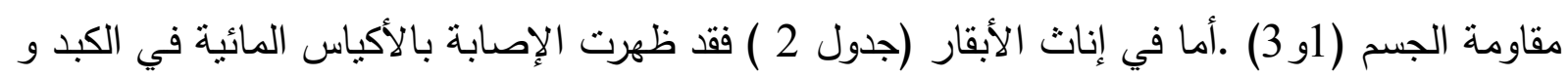

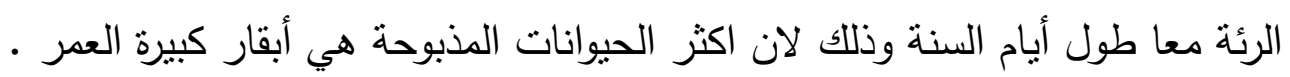


كان عدد الأكياس المائية في العجلات صغيرة العمر في الكبد وكذللك في الرئة قليل لوجود علاقة طردية

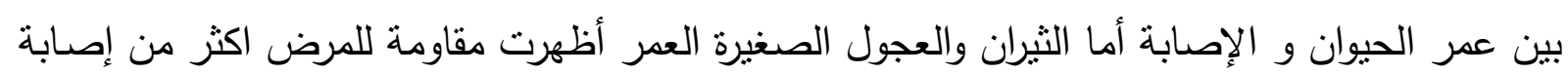

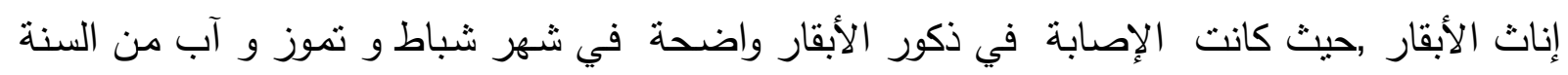

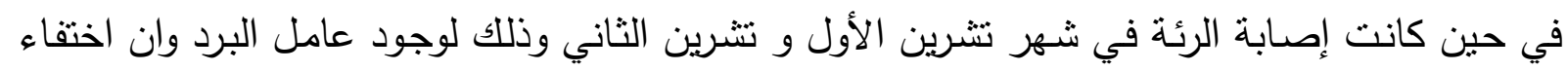

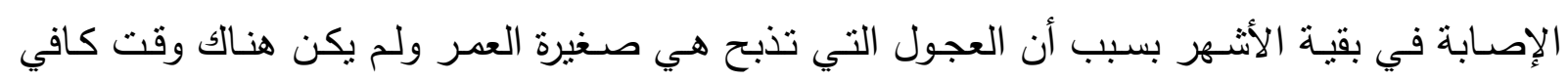

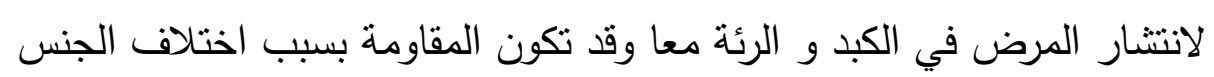

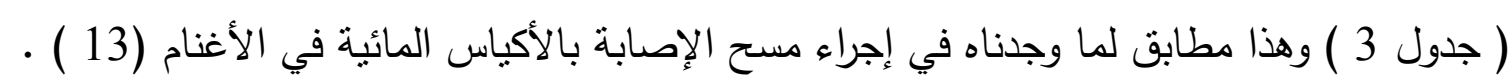

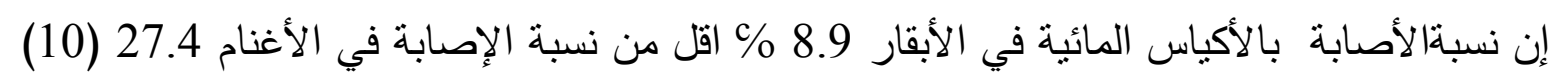

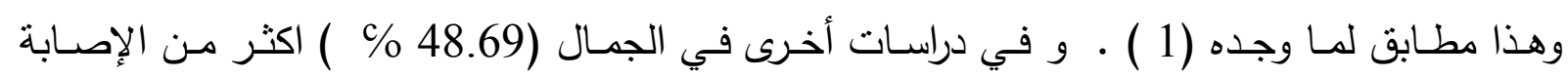

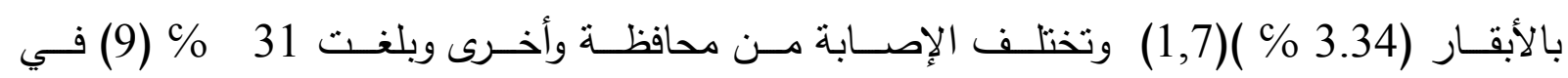

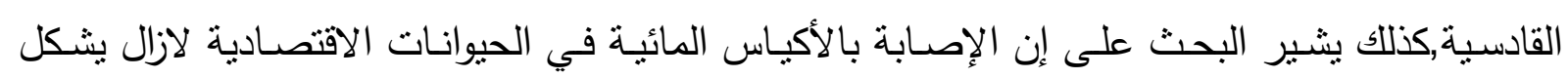

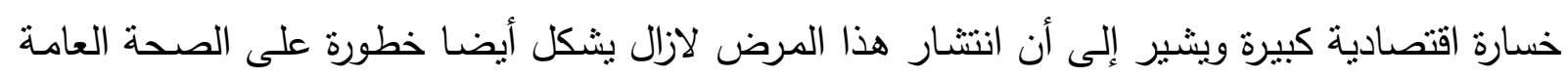

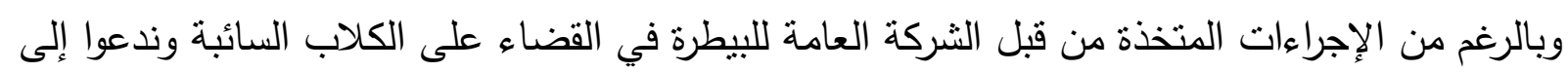

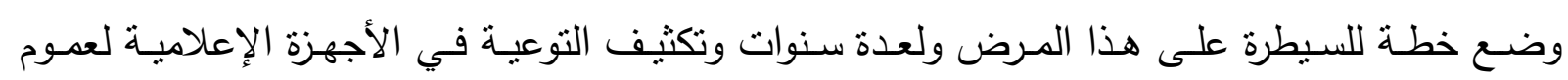

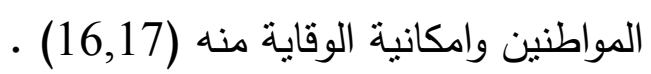

\section{المصادر}

1. Saad, M.B., Magzoup.M.(1989).Hydatidosis in camel and cattle in Sudan. Sud.J.Vet.Sci. Anim.Husb.

2. Matossian,R.M.Rickard,M.D.and Smytl,J.D.(1977).Hydatidosis,aglobal problem of increasing importance.Bull.WHO.,55(4) 459-507.

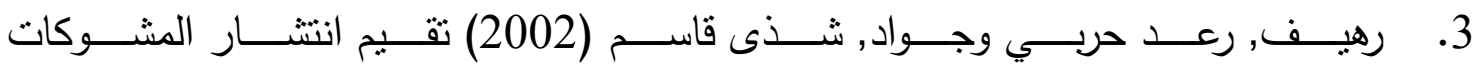
الحبيـةEchinococcus granulosus في بغداد ,المؤتمر العلىي الخامس للأمراض فئس

$$
\text { المشتركة في بغداد/كلية الطب البيطري • }
$$

4. Polydorou, K. (1982), Report on echinococcosis, hydatidosis, director department of veterinary service, Nicosia-Cyprus.

5. Schwabe, C.W. (1968).Epidemiology of echinococcosis.Bul.WHO.39, 131135.

6. رهيف,رعد حربي و منير عبد الأمير (2002) انتثار داء الأكياس العذرية في الإبل في العراق /المؤتمر العلمي الخامس للأمراض المشتركة في / كلية الطب البيطري . 
7. الصقر ,إحسـان مهدى ,العباسـي ,صباح نـاجى ,الطيف ,خليل إبراهيم (1977) الأكياس

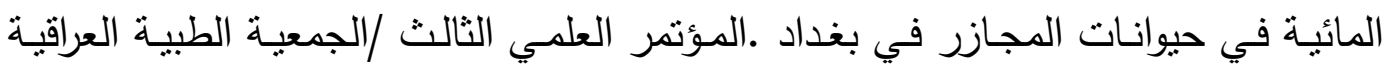
/بغداد.

8. مدلول ,هادى •و داود رخيري عبد الله (2002) دراسة وبائية الأكياس العدرية في منطقة

الديوانية /المؤتمر العلمي الخامس للأمراض المشتركة في بغداد -كلية الطب البيطري .

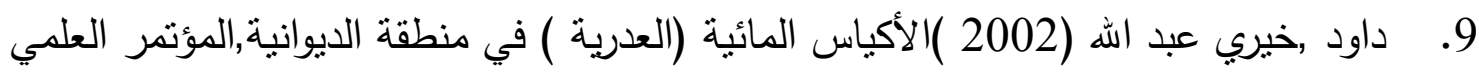
الخامس للأمراض المشتركة في بغداد كلية الطب البيطري .

10. 10-Nelson, G.S.and Rosch,R.I.(1963) .Echinococcosis in man and animal in Keenya.Ann.Trop.Med.Parasite.57,136-149.00

11. Eias, M.M. (1962).Preliminary survey of hydatidosis systicercosis. Sud. Jur. Of Vet. SCI \&animal husbandry. Volume 3, No.2 Page 103.

12. 12-El.Khawad, S.E., Eias, A.M.Ibrahim, A.M.Sleneve, W.K.\&EI.Gezuli, A.Y.incidence of Helminth parasites in Ruminant slaughtered in the western provinces of Sudan,Sud.J.Vet.Sci. 